\title{
Fleet planning and technology upgrade projects: supporting decision-making through visualisation
}

\section{Clive Kerr}

Centre for Technology Management

Institute for Manufacturing

University of Cambridge

17 Charles Babbage Road, Cambridge, CB3 0FS, United Kingdom

E-mail: civk2@cam.ac.uk

*Corresponding author

\section{Simon Ford}

Beedie School of Business

Simon Fraser University

250-13450 - 102 Ave, Surrey, British Columbia, V3T 0A3, Canada

E-mail: simon_ford@sfu.ca

\begin{abstract}
In project planning, visualisations can be powerful tools for communication and in supporting decision-making between stakeholders. However the graphical elements, in terms of form and presentational style, are typically poorly treated and can therefore diminish both the impact and conveyance of information. Traditional timeline representations need to be adapted and modified in order to meet the requirements of specific stakeholder groups and thus fulfil their role as effective visual boundary objects. This paper describes the visualisation designed and developed for the planning of technology upgrade projects across a fleet of military platforms. A real-world application of the visualisation is provided through an illustrative case study based on the front-line fleet of Type 23 frigates of the Royal Navy.
\end{abstract}

Keywords: project planning; boundary object; visual communication; visualisation; timeline; roadmapping.

Biographical notes: Clive Kerr joined the Centre for Technology Management at the University of Cambridge in 2005. As a Senior Research Associate, he conducts research in the field of strategic technology management. His research interests are visual strategy, roadmapping, management tools/toolkits, and technology intelligence. Prior to joining Cambridge, he was a Research Officer at Cranfield University. He has a First Class Honours degree in Electrical and Mechanical Engineering, a Diploma degree in Economics, a Postgraduate Certificate in the Social Sciences and a Doctorate in Engineering. He is a Chartered Engineer with professional memberships of the IMechE, IET, RAeS and AIAA.

Simon Ford is a Lecturer at the Beedie School of Business at Simon Fraser University, and was previously a Senior Research Associate at the Centre for Technology Management, University of Cambridge. His research activities span work on technology and innovation management, industry emergence and evolution, and 3D printing, sustainability and the circular economy. Simon completed his $\mathrm{PhD}$ at the Centre for Technology Management in 2007 on the 


\section{Introduction}

Within the field of project management, timelines are the most fundamental visual representation used in planning. They can serve a wide range of functions (Yakura, 2002). Typically traditional forms of timelines, such as Gantt and PERT, are applied to support optimisations and control (Taxén and Lilliesköld, 2008) whereas newer visual forms are being developed for the purposes of understanding, negotiation, coordination and action (Chang et al., 2013; Taxén and Lilliesköld, 2008). Although the power of visual planning tools is widely recognised, their actual graphical depiction and presentational style is either overlooked or poorly treated. Visuals can provide an effective means for displaying and communicating project planning information to support decision-making (Killen and Kjaer, 2012), but only if the specific visualisations are designed with proper attention being given to how the actual visual objects/components are displayed.

To illustrate the visual aspects of project planning imagery, this paper presents a real-world example of a planning tool developed for the UK Ministry of Defence and the Royal Navy. The case study material, which focuses on the Type 23 Duke-class frigates that represent the core of the Navy's front-line fleet (Royal Navy, 2012), fits within the project management domain in terms of planning multiple projects - in this case, to upgrade and update operational systems across a group of naval vessels (i.e. platforms). The aim for developing the visual depiction was to support the decision-making in regard to the fleet management challenge of planning technology upgrades during the operational through-life of the Type 23 frigates out to 2035. Naval combatant platforms have active service lifecycles in the order of decades. Therefore, they require enhancements to their functional capabilities and performance levels in order to keep pace with the latest advances in technology in order to respond to the "challenges posed by evolving military threats, problems with reliability and subsequent maintenance costs, risks of obsolescence, and diminishing manufacturing sources" (Kerr et al., 2010). The visualisation of the Fleet Upkeep Plan provides a means for structuring, comparing, contrasting and presenting supporting evidence within the submission process of the Type 23 Through-Life Management Plan. It is hoped that this example might act as a reference case which highlights the 
need to critically address the graphical design elements and visual conventions applied when developing project planning visualisations. Essentially, it provides an illustrative example which stresses that the visual representational and presentational perspectives must be adequately considered in order for a visualisation to meaningfully embody and effectively convey the essence of a plan.

\section{Visualisation and sensemaking}

Visualisations have an important role to play in the construction and communication of meaning; they are essential constructs in sensemaking processes (Meyer et al., 2013). Furthermore, the demands placed on visualisations are "best viewed as interdisciplinary, requiring not just simultaneous parallel use but truly joint utilisation and team-wise sensemaking for effective decisions" (Bendoly, 2016). Bendoly (2016) provided an initial exploration of the functions of data visualisations in enacted sensemaking (e.g. mapping, filtering, comparing, discussing). Although the original basis for enacted sensemaking had a retrospective lens, it is the prospective orientation (Gioia et al., 1994; Gioia and Mehra, 1996) that is of particular relevance to project management and planning since its focus is: "the conscious and intentional consideration of the probable future impact of certain actions, and especially nonactions, on the meaning construction processes" (Gioia et al., 1994). Intertwined with sensemaking is the symbiotic dimension of sensegiving, i.e. "to influence the way that another party understands or makes sense" (Gioia and Chittipeddi, 1991). Garreau et al. (2015) attempted to explain how practitioners perform sensemaking/giving with visual representations and elicited a number of associated modes. They identified that the underlying pattern for sensemaking is one of content-generating, whereas sensegiving is content-ingraining. For sensemaking, visualisations are a 'window' on strategic content which "not only enables people to address new insights, but also provides an opportunity for developing a collective understanding of a situation" (Garreau et al., 2015). In terms of sensegiving, visualisations are in essence a 'mirror' which aims to influence perceptions and understanding of the content (Garreau et al., 2015). It is important to recognise and acknowledge that the same visual representation can be used differently, i.e. a single visualisation can be used as both a window to strategic content and as a mirror reflecting the organisational setting (Garreau et al., 2015).

Meyer et al. (2013) have called for research on the visual aspects; in particular, to consider "how visual cues in the everyday use of managerial instruments guide attention by selectively presenting information, and, 
thus, support - but also constrain - decision-making". In sensemaking, Weick (1995) stresses the importance of extracted cues. As stated by Weick (1995): "although content is a key resource for sensemaking, of even more importance is the meaning of this content. And that meaning depends on which content gets joined with which content, by what connection. Content is embedded in cues, frames, and connections". In regards to embedding content into visuals and then cueing/prompting the extraction of meaning, it is important to recognise that visualisations are composed of two layers, namely: (i) representation, and (ii) presentation. The representational layer defines the "underlying information-based structure" (Phaal and Muller, 2009), i.e. the format, hierarchy and layout on the page. Whereas the presentational layer defines the aesthetic style, including colour, used to present and give emphasis to its contents. For project planning visualisations to be effective in supporting decisionmaking, graphic design knowledge must be applied to enhance the presentation of information. The challenge is to communicate a large/complex amount of data in an intuitive format ensuring the appropriate content for the specific audiences. This involves achieving a balance between function and aesthetic form. For a visualisation to engage with an audience it must attract attention, sustain interest and relate to their sensemaking abilities. However, it must be remembered that it is not about impressing an audience with a beautiful visualisation, but rather informing them of the key information through facilitating their comprehension of the content and its context through the explanatory power of visual communication.

When confronted with a visualisation and attempting to make sense of the content being depicted and its embodied meaning, the perception of cues (i.e. 'noticing') is critical. According to Starbuck and Milliken (1988), noticing is about 'looking for what matters' (i.e. where to look and what to see); and, sensemaking is then about 'what it means' (e.g. interpreting and comprehending). The act of noticing, by which cues are extracted for sensemaking, relies upon perceptual filtering - the process that amplifies some stimuli and attenuates others, thus focusing attention (Starbuck and Milliken, 1988). For visualisations, there are two attentional mechanisms: (i) bottom-up, and (ii) top-down (Bojko, 2013; Connor et al., 2004; Corbetta and Shulman, 2002; Kastner and Ungerleider, 2000; Katsuki and Constantinidis, 2014; Ocasio, 2011). Bottom-up attentional influence is exogenous (i.e. externally induced) and stimulus-driven meaning that attention is involuntarily shifted, or guided, to salient objects based on their inherent visual properties/characteristics (e.g. colour, line thickness, etc.) in contrast to their relative surroundings/background. Hence, the need and importance for 'good' graphic design practices on the presentational layer of project planning visualisations. 
Top-down attentional influence is endogenous (i.e. internally induced) and goal-driven meaning that information is actively sought out and attention is voluntarily/intentionally directed to relevant objects deemed important based on cognitive factors (such as task demands, expectations, experience and prior schematic orientation). Thus, the representational layer of a visualisation must be carefully designed and developed in order to effectively support top-down attention. So that top-down processing is indeed purposeful for the task-at-hand, in terms of sensemaking, project planning visualisations should be underpinned by appropriate functional frameworks. It is the putting of content/stimuli into frameworks that actually enables people to comprehend, explain, attribute, extrapolate and predict (Starbuck and Milliken, 1988; Weick, 1995). Stigliani and Ravasi (2012) highlight the aggregating/integrating of content through the practice of 'frameworking' in order to produce visual representations that embody connections. The resultant visual artefact should then allow for better understanding of the different elements of the task (in this case, the 'plan'). For project planning purposes, it is essential for the framework to reflect connections and allow these connections to be traced. Such connections allow for sensemaking of causality, association and sequences (Stigliani and Ravasi, 2012). As acknowledged by Weick (1995) "sequencing is a powerful heuristic for sensemaking" and sensemaking is about action: "if the first question of sensemaking is "what's going on here', the second, equally important question is "what do I do next"" (Weick et al., 2005). This, of course, is very pertinent in the context of project management and planning. The intent for the visualisation of the Fleet Upkeep Plan, reported in this paper, is to provide a means to structure/integrate, compare, contrast and present the elements constituting the plan. In order to realise this from a sensemaking/giving stance and enable top-down processing, the representation adopts the condensed visual format of a technology roadmap so as to provide a 'one-page highlevel systematic view' and is underpinned by the conceptual framework of Phaal (Phaal and Muller, 2009; Phaal et al., 2008). The architecture of the framework consists of two fundamental components:

- Timeframe (i.e. 'know-when') - which encompasses the short-, medium- and long-term perspectives, as well as aspirations/vision (Note: the convention is to orient the time dimension to the horizontal axis).

- Systems-based hierarchical taxonomy - this embodies the 'knowwhat', 'know-how' and 'know-why' knowledge and allows for different levels of detail to be addressed (Phaal and Muller, 2009).

For the Fleet Upkeep Plan, which will be described in full in Section 5, the 'know-when' and 'know-how' aspects are most important and are 
therefore centrally positioned within the visualisation. They correspond to the upkeep cycles and individual vessel fleet time commitments (see Section 5.1). The 'know-why' equates to the fleet-wide profile (Section 5.2) and an assessment of critical capability areas (Section 5.3). The upgrade projects then reflect the 'know-what' (Section 5.4).

\section{Visualisation in support of project planning}

Timelines are considered as crucial tools by managers for project planning (Yakura, 2002); although it must be noted that this assertion has existed since the early days of Henry Gantt's introduction of the use of bars on a horizontal-time axis for representing work/task durations in schedules. Figure 1 depicts one of the first published Gantt charts (Gantt, 1919). Having witnessed the impact of Gantt's work, Trabold (1923) stated that "without charts an executive is utterly helpless". Clark (1923), a contemporary of Gantt, even declared that the Gantt chart was the 'most notable contribution to the art of management' in their generation and remarked that "the plan is presented so clearly that it can be understood in details as a whole not only by the executive himself but also by those above him and by his subordinates".

It is worthy to note that one of the first significant application areas for the Gantt chart was in the defence industry during the First World War. Henry Gantt's visual representation was used by the US Ordnance department, the Navy, the Emergency Fleet and the Shipping Board (Clark, 1923; Gantt, 1919). Of particular note, especially given that this paper focuses on a naval case study, is a specific application developed by Gantt for charting ship movements of the American Merchant Marine Fleet (Clark, 1923) as shown in Figure 2.

From considering the aspect of time through an organisational perspective, Hassard (1991) has highlighted that timelines are powerful representations because of the basic temporal functions that they address, namely:

- "The need for schedules, i.e. for reliable predictions of the points in time at which specific actions will occur".

- "The need for synchronisation, i.e. for temporal co-ordination among functionally segmented parts and activities".

- "The need for time allocation, i.e. for distributing time so that activities will consume it in the most effective and rational way".

The visual manifestation of timeline representations is reinforced by Yakura (2002), who acknowledges that "the practice of charting time is 
inherently visual, a fact that contributes to its taken-for-granted nature (after all, 'seeing is believing')". Of course, the most common or dominant types of visualisations correspond to those of Gantt charts and PERT diagrams (Taxén and Lilliesköld, 2008). Such forms are classified as 'sequencing/planning' visualisations by Eppler and Platts (2009).

It is important to recognise that the traditional forms of timelines have been criticised and their emergent weaknesses identified when considering the present-day challenges faced by project management practitioners. One of the most clearly articulated analysis of this situation has been produced by Taxén and Lilliesköld (2008), who contend that the traditional visual forms were developed "before the boost of complexity" and thus their functional contribution in certain specific areas is lacking. Taxén and Lilliesköld (2008) acknowledge that "the primary purpose of the traditional images is to control planned actions, and in addition, optimise time and effort"; however they highlight that "these images were not devised to support tasks such as: creating a common understanding of the work, supporting the project to align itself with moving targets and emerging fuzzy goals, and taking decisions regarding changes".

In parallel to the critical reflection on the functional utility of traditional timeline representations, there is increasing attention being concentrated on the subject of boundary objects and their potential role within the project management domain. For instance, in the context of negotiations of project contracts, Koskinen and Mäkinen (2009) have embraced the boundary object as "a means to achieve a shared understanding" between stakeholders where such objects as project plans can serve as interfacing tools. The strongest support in the literature for the consideration of visual boundary objects in project management is from Yakura (2002), who puts forth the argument that "timelines function as temporal boundary objects that make time concrete and negotiable for various groups of participants". Yakura (2002) positions timeline representations as boundary objects because they can act as focal points for interpretation, discussion, negotiation and co-ordination.

Adopting the concept of boundary objects and the view of project plans as 'focal points' for engagement at the interfaces between stakeholders, a potential route to addressing some of the criticisms of traditional timelines and resolving the functional weaknesses of their visual representations is emerging. For instance, Chang et al. (2013) have generated a modified timeline representation to act as a boundary object to help facilitate negotiation, co-ordination and cohesion within a large complex project environment. To make further progress along this path, it is critical to first acknowledge and then strongly emphasise that as boundary objects the 'plan as visual artefact' means that the components of the visualisation must be examined and designed purposely. This is because it is the visual 
patterns and their depiction that conveys the meaning (Kerr et al., 2012a). Thus, the representation and presentation aspects have the greatest impact on the subsequent interpretation of a plan's information content by its audience. As stated by Blankevoort (1984): when making a plan, "one of the most difficult tasks is to tell someone else what you wish to achieve for the future". 'Project plans as boundary objects' is essentially about 'good' communication; given that plans are images/diagrams, the challenge is one of visual communication in order to support the functions of understanding, negotiation, decision-making and co-ordination. For instance, in multi-disciplinary multi-national projects, "the effectiveness of information and its communication are essential to establishing shared understanding" (Fox, 2009). Additionally, Fox (2009) reinforces the need to seek improvement in the effectiveness of project information through visual communication (via better information design / graphic design practice).

In considering the application of visualisation methods to the field of project management, Blankevoort (1984) states that "the word 'visualise' demonstrates that the mind is working more with whole pictures than with sequential lines of reason". Even in regard to traditional Gantt charts, Taxén and Lilliesköld (2008) acknowledge that "if the diagrams become larger than one page, they are not useful for communication or discussions". Adopting the idea of 'one-page systematic views' from the strategic planning method of roadmapping, 'plans on a single page' offer a medium for ensuring "that the key issues are focused on, set against the context provided by the 'big picture' view" (Phaal et al., 2008). Such "one-page views can also be updated more easily, enabling the process to be more agile" and allows a plan "to keep pace with the rapidly changing business situations" (Phaal et al., 2008). Thus, the principal challenge is to concisely summarise the key information, including the necessary background details, onto a single page in a manner that is meaningful for particular audiences. It requires balancing the functional and aesthetic form in order to produce an easily understandable image with an intuitive representational format, appropriate style of presentation, and associated conventions.

To reinforce the need to appropriately address the visual aspects of project planning depictions and to generate new forms of timeline-based representations, this paper depicts an actual real-world tool that was developed for application as a visual boundary object. This example is from the defence industry and its purpose was to support decision-making and communication between a number of stakeholders involved in the planning of multiple upgrade products across multiple maritime vessels within an active in-service fleet. Examples from the defence industry have the potential to act as pertinent reference case studies. The industry has 
been greatly impacted by changes in spending which makes "the quality and timeliness of decisions more critical to success" (Omar and Kleiner, 1997). There is the need for tools to support the effectiveness of decisionmaking in deploying the limited resources available for projects and visual approaches are identified as a mechanism to help achieve this - "the more visual the method, the more apparent is the course of action" (Omar and Kleiner, 1997). Initial progress has been made within the defence industry to realise the potential of visual planning boundary objects. For example, Chang et al. (2013) reported on the use of the Integrated Master Schedule to assist decision-making between stakeholders when unplanned events emerge. However in terms of addressing the actual 'visual' side of visualisations, the reported examples in the literature have been orientated more to the area of strategic planning. For instance, there is the transformation mapping approach applied to the Royal Australian Navy's Surface Combatant Fleet which plots the timeframe of the "life-of-type extensions and out-of-service dates of the active fleet along with the inservice dates of the next generation replacements" (Kerr et al., 2011). Embedded within its visual framework-based template is relevant project management information relating to "acquisition cost, complexity of project management, schedule constraints, technical difficulty, operation and support readiness" (Kerr et al., 2011). There is also the case study based on an US Army programme which has a visual representation depicting alternative procurement plans (Kerr et al., 2012b) - its specific aim was to provide a visual means to compare and contrast the different options. Each of the options was illustrated using a common visual language where specific graphical components were used to convey particular information, for example:

- An options grid was used to outline the key attributes for the current plan and option set.

- A pie chart was used to express the percentage share of the budget allocated to the current plan.

- A Sankey diagram was used to provide a quantification of R\&D expenditure and procurement cost.

- A Gantt chart was used to depict the timings for the staged introduction of programme elements.

- A table was used to outline the total cost, likely cost growth and total cost under the worst-case scenario. 


\section{Fleet planning and technology insertion}

The emphasis in project planning for today's defence industry has shifted to a resource-constrained context and a dynamic external environment. Military product platforms (e.g. aircraft, ships, ground vehicles) have to remain in active service far beyond their original design life as funding pressures impact the timely introduction of new successor platforms. With this trend of extended operational lifecycles, there is the need to continually consider the upgrading of platform systems and associated performance levels against such drivers as the changing role of military forces and the rate of technological progress (Kerr et al., 2010). Thus, the focus in planning is orientated to 'technology insertion' - the insertion of new or improved technologies into a legacy product platform in order to refresh and enhance its operational functionality (Kerr et al., 2008). What is now taking place is essentially a process of "platform modernisation via technology insertion" (Kerr et al., 2011).

In relation to the need for visualisations to support fleet planning of upgrade projects (via technology insertion processes), the challenge is to generate a single-page systems view that can act as a focal point for the various stakeholders (e.g. Fleet Headquarters, Requirement Managers, Project Planners, Maintenance Schedulers) that enables them to "outline future capability requirements, determine product development options, and align these with the associated technology upgrade paths against the time dimension" (Kerr et al., 2011). To illustrate an actual example of how this can be achieved, this paper presents a case study based on the Royal Navy's fleet of Type 23 frigates and discusses/highlights the visual components of this new form of planning visualisation.

The aim of the visualisation is to provide a means to establish a shared understanding and to support the process of mediation/negotiation around specific constraints and bottlenecks. In this regard, in applying the visualisation as a tool for fleet support decision-making, one of the principal benefits of the visualisation is to identify occasions when the Sea Trials (where the system upgrades are tested) exceed their allocated duration and thus clash with the Fleet Time commitments (military operations). A 'clash' means that sea trials are too short for the planned upgrades; hence the stakeholders must reconsider what combination of technology upgrade packages can be fitted and tested given the fleet date, and then provide a revised estimate for the duration of the sea trials. Thus, the visualisation can be used proactively to discuss and consider alternative upkeep scenarios. That means that this new form of visualisation is orientated to 'action'. As emphasised by Taxén and Lilliesköld (2008) such images "are not only used for reporting purposes - 
they are used as mediational means for anticipating possible actions and foreseeing the consequences of these actions".

\section{Visualising the 'Fleet Upkeep Plan'}

This section of the paper presents and describes the bespoke visual developed for the upkeep planning of the Type 23 Fleet. The visualisation provides two primary functions:

- A means of decision-support and analysis in preparing the Fleet Upkeep Plan.

- As a mechanism for reporting/communicating the proposed/agreed version of the plan.

These dual functions are achieved through the provision of a graphical overview containing the following elements:

- The individual vessel fleet time commitments and upkeep cycles.

- The key upgrade projects with supporting data.

- A fleet-wide profile.

- An assessment across critical capability areas.

The visualisation for the Type 23 Fleet Upkeep Plan is depicted in Figure 3. Note: the image was designed to be printed out in colour on a single A3 sheet. The format is tuned to the stakeholders' needs and the tailored design of the visual representation and presentational style has led to a much greater resonance with its users. Given the nature of the case study and its potential sensitivity, please note that this paper only presents the views of the authors and not necessarily those of the Ministry of Defence or the Royal Navy; the figures are populated with representative data and specific upgrade projects have been given nominal titles.

The visualisation was built using two principal visual forms, namely: a time-based chart and a look-up table. These are shown in Figure 4. The time-based chart is comprised of three layers. The key layer is the Ganttstyle Main Schedule, depicted in Figure 5, which plots the fleet time elements (fleet time periods, non-taskable fleet time, fleet time support periods) and non-fleet time elements (refit periods, docking periods, sea trials) across the whole of the Type 23 Fleet. Above the Main Schedule is the Fleet Profile layer, see Figure 5, which gives a quantitative summary of the number of vessels in fleet time, sea trials, upkeep and, when applicable, the number of vessels withdrawn from service. Additionally, the Fleet Profile highlights potential scheduling conflicts where a vessel is planned to return to fleet time but its sea trials are likely to overrun the 
agreed date of handover to fleet operations. Below the Main Schedule is the Fleet Capability layer (Figure 5). This provides an indication of the targets for future capability assessments, on a yearly basis, using a traffic light grading scheme. Below the time-based chart is the look-up table (as indicated in Figure 4). This table provides a summary of the upgrade projects, termed Alterations and Additions (A\&As), together with supporting data (e.g. fit type, initial service date, dependencies, impact on ship, etc.) alongside the corresponding year of fitting allocated for each vessel. The table also highlights the vessel being the first-of-class to receive each specific A\&A and the corresponding last vessel in the class to be fitted.

\subsection{Vessel operating and upkeep cycles}

Within the time-based chart, the principal layer is the Main Schedule. This is the most important part of the visualisation; as such, it is the most visually dominant by being both in the middle of the graphic and having the largest visual area in the graphical layout. It depicts the operating fleet times and upkeep cycles for each vessel across the Type 23 Fleet. The fleet is split into the eight Sonar 2087 Tail vessels and the five General Purpose vessels. The ordering of vessels within these two categories is arranged alphabetically by vessel name with the associated pennant number also being given for reference purposes.

Each vessel has its own dedicated horizontal row running across the visualisation. These rows give, in a parallel fashion, both the Fleet Time Schedule (the upper part of the row) and Upkeep Cycle (the lower part of the row) as can be seen in Figure 6. The Fleet Time Schedule is essentially a number of blue bars that show when the vessel is to be in Fleet Time (FT). Within each of the blue bars are a series of thin vertical black bars (Figure 6) - these represent the Fleet Time Support Periods (FTSPs). They typically occur twice a year, for a duration of four weeks (the width of the vertical black bars). The other embedded element in the Fleet Time bars is the Non-Taskable Fleet Time (NTFT) - this appears as a light blue section at the front-end (left-hand side) of the Fleet Time bar (Figure 6). They only occur when a first-of-class A\&A is fitted and are used to indicate an extra allocation of time post-sea trials.

The Upkeep Cycle consists of a number of compound bars (Figure 6) these are tagged as being either a planned Docking Period (DP) or a planned Refit Period (RP) and numbered sequentially according to type (e.g. DP1, RP1, DP2, RP2, etc.). The compound bars consist of two parts, namely: (i) the actual fitting period (coloured purple), and (ii) the associated sea trials period (coloured orange). The Upkeep bars are also tagged with two key dates. At the start of the bar is the Non-Fleet Date 
(NFD) and at the end of the bar is the Fleet Date (FD). When a vessel is planned to be withdrawn from active service, its out-of-service is shown by the large grey sections that span across to the right of the visualisation as indicated in Figure 6.

A critical function of the Main Schedule is to highlight any conflicts in the timelines between the vessel fleet times and their periods of upkeep. Problems arise when the duration of the sea trials is potentially longer than estimated and thus overruns the agreed fleet date. If this occurs, the conflict in scheduling is signalled by a red section being coloured in the Sea Trials bar (at its end) - an example is illustrated in Figure 6. These red sectioned bars are the key visual features to look out for in the main scheduling layer because they identify scheduling conflicts in the fleet plan.

\subsection{Fleet profile}

The Fleet Profile layer serves two purposes: (i) it provides a running total on the number of vessels in different states of operation, and (ii) highlights any potential scheduling conflicts.

The top two rows of the Fleet Profile (Figure 7), named Clash (2087) and Clash (GP), are used to highlight potential conflicts (i.e. clashes) in scheduling between the vessel fleet time commitments and their upkeep cycles across both the Sonar 2087 and General Purpose fleets. The Clash (2087) and Clash (GP) rows are generally blank indicating no potential problems in the schedule. If there is a conflict, as caused by the sea trials duration running longer than estimated and thus impacting on fleet time, a red numeral appears in order to indicate the number of vessels with this scheduling problem (as illustrated in Figure 7). This warning error in the Fleet Profile corresponds to the red sections in the Sea Trials bar that occurs in the Main Schedule (Figure 6). of:

The remaining rows of the Fleet Profile give a quantitative summary

- Fleet Time (2087) - the number of Sonar 2087 Tail vessels in fleet time (as per the blue coloured Fleet Time bars in the Main Schedule).

- Fleet Time (GP) - the number of General Purpose vessels in fleet time (as per the blue coloured Fleet Time bars in the Main Schedule).

- Sea Trials - the combined number of Type 23 vessels in sea trials (as per the orange coloured sections of the Upkeep Cycle bars in the Main Schedule). 
- Upkeep - the combined number of Type 23 vessels in Docking Periods or Refit Periods (as per the purple coloured sections of the Upkeep Cycle bars in the Main Schedule).

- Out-of-Service - the number of Type 23 vessels planned to be withdrawn from operational use (as per the grey coloured bars in the Main Schedule).

It must be noted that the Fleet Profile does not explicitly report the number of vessels in either Non-Taskable Fleet Time (NTFT) or Fleet Time Support Periods (FTSPs) as these two states are technically considered as Fleet Time (either 2087 or GP depending on the vessel).

In addition to highlighting any clashes between the Fleet Time and Sea Trials, there are two other warning indicators that can be displayed (Figure 7):

- Deficits of vessels in Fleet Time (i.e. too few vessels available for operations) are highlighted by a red shaded cell with the number given in white text.

- If there are too many vessels scheduled for Upkeep, the cell background shading will change to purple with the number of vessels given in white text.

\subsection{Capability assessment}

The Fleet Capability (Figure 8), which is the bottom layer in the timebased chart (Figure 5), provides a visual indication of the targets for future capability assessments. These capability assessments are on a yearly basis and across nine capability areas, namely:

- Personnel safety and ship safety;

- Anti submarine warfare;

- Anti air warfare;

- Command, control and communications;

- Anti surface vessel warfare;

- Structure, damage, integrity;

- Machinery and systems;

- Protection of the environment;

- Habitability.

The capability areas are graded using a traffic light colour scheme where: 
- Red - equates to major deficiencies.

- Yellow - equates to minor deficiencies.

- Green - equates to sufficient capability.

\subsection{Upgrades}

The look-up table (as depicted in Figure 4) contains the data relating to the Alterations and Additions (A\&As), essentially upgrades and updates to ship systems and equipment, that are planned to be fitted during the various docking and refit periods of the upkeep cycles. Each specific A\&A is both named (i.e. project title) and numbered for reference purposes, and appear as a single horizontal row running across the look-up table. Alternating rows are background shaded in grey (versus white) for ease of viewing.

The left-hand side of the look-up table (Figure 9a) provides the corresponding supporting data for each A\&A and includes:

- Fit Progress - the number of vessels fitted against the number to be fitted across the fleet (if the fitting of a specific A\&A is already underway then the numerals are coloured purple).

- Fit Type - the appropriate type of fitting period necessary given the length of time required to make the actual fit (i.e. RP only or either a $\mathrm{DP} / \mathrm{RP}$ or any FTSP/DP/RP).

- Initial Service Date (ISD) - the year of the first-of-class fit or the Underway annotation indicating that the fitting of the specific A\&A is already in progress and being rolled-out across the fleet.

- A\&A Dependencies - other A\&As that must be fitted either before or with that specific A\&A.

- Impact on Ship - the intrusiveness and difficulty of the fit on the vessel (i.e. High, Medium, Low).

- Risk to First Fit - a measure of the risk associated with attempting to make the first-of-class fit (i.e. High, Medium, Low).

- Fit Duration - the number of weeks needed to make the fit for both the first-of-class (First) and normal (Norm) rollout across the fleet.

The right-hand side of the look-up table (Figure $9 \mathrm{~b}$ ) is focussed on the vessels and is orientated in a similar manner to the Main Schedule layer of the time-based chart - just transposed from a vertical to a horizontal layout. The fleet is split into the Sonar 2087 Tail and General Purpose vessels. They are arranged in the same order as the Main Schedule but 
with only the pennant numbers being given for identification purposes. The horizontal column-based layout provides a cell for each A\&A against the corresponding vessels in order to indicate either:

- The planned year for fitting.

- If already fitted.

- Won't be fitted (indicated by an $X$ in the cell).

For each specific A\&A, the vessel representing the first-of-class fit is depicted by a purple coloured cell with yellow text whereas the last vessel in the feet to be fitted is indicated by a blue cell with white text.

\section{Summary}

The through-life management of maritime vessels is a complex process; there are the competing demands of operational availability and the need to update capabilities (based on gaps or shortfalls in functionality and/or performance levels), scheduling of maintenance, risks of obsolescence, and advances in technology. A lot can change over the 20-40 years or so time period while vessels are in service. One of the critical challenges is the planning of technology insertion projects during the in-service phase of the product lifecycle. Numerous stakeholders are involved and communication can be problematic in regards to how best to direct and coordinate the flow of technology for platform modernisation. Traditional project planning visualisations need to be either adapted, redesigned or even completely replaced by alternative visual forms in order to enable a more proactive means of developing a better shared understanding between stakeholders and support their collaborative decision-making. A new form of planning visualisation has been developed, for use by the UK Ministry of Defence and the Royal Navy, to act as a visual boundary object for structuring, comparing, contrasting and presenting Fleet Upkeep Plans. As articulated by the Requirements Manager of the Type 23 Fleet: "What we require is an effective long term planning tool, which easily represents the interdependencies between projects and also ships' programmes". With the development of this new visualisation, it is the first time that a single tool has "combined the range of functions to give a clear, concise, visual 'plan on a page' to see where potential conflicts or bottlenecks are that could give rise to problems, and allowing planners to juggle the needs of the fleet, maintenance activity and enhancements, accordingly". The visualisation permits two main uses, namely: (i) a means of decision-support and analysis in preparing the Fleet Upkeep Plans, and (ii) as a mechanism for reporting/communicating such plans. 
The format can be used to resolve potential conflicts (clashes) in scheduling and errors in the planning, and to explore alternative upkeep scenarios. For instance, as highlighted by the Type 23 Requirements Manager: "the tool helps us to visualise and understand these interdependencies and relationships, so that, for example, we are not going to suddenly fit a piece of equipment and find it does not work because we haven't upgraded the electrics". The visual canvas of the Fleet Upkeep Plan is comprised of four components:

- The main schedule, which plots the fleet time elements (fleet time periods, non-taskable fleet time, fleet time support periods) and nonfleet time elements (refit periods, docking periods, sea trials) across the whole of the Type 23 Fleet.

- The fleet profile, which displays a running total on the number of vessels in different states of operation and highlights any potential scheduling conflicts.

- The capability measures, which provide an indication of the targets for future capability assessments depicting areas of major/minor deficiencies.

- The technology upgrade projects, which takes the form of a look-up table containing the data relating to the alterations and additions to the ship systems and equipment, that are planned to be fitted during the various docking and refit periods of the upkeep cycles.

The visualisation and associated case study reported in this paper emphasises the need for the project management community to purposely consider the meaningful design of graphics and appropriateness of the visual form for the application of timeline-orientated images as boundary objects.

\section{References}

Bendoly, E. (2016) 'Fit, bias and enacted sensemaking in data visualization: Frameworks for continuous development in operations and supply chain management analytics', Journal of Business Logistics, Vol. 37, No. 1, pp.6-17.

Bojko, A. (2013) Eye tracking the user experience: A practical guide to research, Rosenfeld Media, New York.

Blankevoort, P.J. (1984) 'Effects of communication and organization', International Journal of Project Management, Vol. 2, No. 3, pp.138147. 
Chang, A., Hatcher, C. and Kim, J. (2013) 'Temporal boundary objects in megaprojects: Mapping the system with the integrated master schedule', International Journal of Project Management, Vol. 31, No. 3, pp.323-332.

Clark, W. (1923) The Gantt chart: A working tool of management, The Ronald Press Company, New York.

Connor, C.E., Egeth, H.E. and Yantis, S. (2004) 'Visual attention: Bottom-up versus top-down', Current Biology, Vol. 14, No. 19, pp. R850-R852.

Corbetta, M. and Shulman, G.L. (2002) 'Control of goal-directed and stimulus-driven attention in the brain', Nature Reviews - Neuroscience, Vol. 3, No. 3, pp.201-215.

Eppler, M.J. and Platts, K.W. (2009) 'Visual strategizing: The systematic use of visualization in the strategic-planning process', Long Range Planning, Vol. 42, No. 1, pp.42-74.

Fox, S. (2009) 'Information and communication design for multidisciplinary multi-national projects', International Journal of Managing Projects in Business, Vol. 2, No. 4, pp.536-560.

Gantt, H.L. (1919) Organizing for work, Harcourt-Brace-Howe, New York.

Garreau, L., Mouricou, P. and Grimand, A. (2015) 'Drawing on the map: An exploration of strategic sensemaking/giving practices using visual representations', British Journal of Management, Vol. 26, No. 4, pp.689-712.

Gioia, D.A. and Chittipeddi, K. (1991) 'Sensemaking and sensegiving in strategic change initiation', Strategic Management Journal, Vol. 12, No. 6, pp.433-448.

Gioia, D.A., Thomas, J.B., Clark, S.M. and Chittipeddi, K. (1994) 'Symbolism and strategic change in academia: The dynamics of sensemaking and influence', Organization Science, Vol. 5, No. 3, pp.363-383.

Gioia, D.A. and Mehra, A. (1996) 'Review of sensemaking in organizations by Karl Weick', Academy of Management Review, Vol. 21, No. 4, pp.1226-1230.

Hassard, J. (1991) 'Aspects of time in organizations', Human Relations, Vol. 44, No. 2, pp.105-125.

Kastner, S. and Ungerleider, L.G. (2000) 'Mechanisms of visual attention in the human cortex', Annual Review of Neuroscience, Vol. 23, pp.315341. 
Katsuki, F. and Constantinidis, C. (2014) 'Bottom-up and top-down attention: Different processes and overlapping neural systems', The Neuroscientist, Vol. 20, No. 5, pp.509-521.

Kerr, C.I.V., Phaal, R. and Probert, D.R. (2008) 'Technology insertion in the defence industry: A primer', Journal of Engineering Manufacture, Vol. 222, No. 8, pp.1009-1023.

Kerr, C.I.V., Phaal, R. and Probert, D.R. (2010) 'Ranking maritime platform upgrade options', Journal of Engineering for the Maritime Environment, Vol. 224, No. 1, pp.47-59.

Kerr, C.I.V., Phaal, R. and Probert, D. (2011) 'Mapping platform transformations', in Ng, I., Parry, G., Wild, P.J., McFarlane, D. and Tasker, P. (Eds.), Complex engineering service systems: Concepts and research, Springer-Verlag, London, pp.375-393.

Kerr, C., Phaal, R. and Probert, D. (2012a) 'Cogitate, articulate, communicate: The psychosocial reality of technology roadmapping and roadmaps', R\&D Management, Vol. 42, No. 1, pp.1-13.

Kerr, C., Phaal, R. and Probert, D. (2012b) 'Depicting options and investment appraisal information in roadmaps', International Journal of Innovation and Technology Management, Vol. 9, No. 3, pp.1-19.

Killen, C.P. and Kjaer, C. (2012) 'Understanding project interdependencies: The role of visual representation, culture and process', International Journal of Project Management, Vol. 30, No. 5, pp.554-566.

Koskinen, K.U. and Mäkinen, S. (2009) 'Role of boundary objects in negotiations of project contracts', International Journal of Project Management, Vol. 27, No. 1, pp.31-38.

Meyer, R.E., Höllerer, M.A., Jancsary, D. and van Leeuwen, T. (2013) 'The visual dimension in organizing, organization and organization research: Core ideas, current developments and promising avenues', The Academy of Management Annals, Vol. 7, No. 1, pp.489-555.

Ocasio, W. (2011) 'Attention to attention', Organization Science, Vol. 22, No. 5, pp. 1286-1296.

Omar, T.A. and Kleiner, B.H. (1997) 'Effective decision making in the defence industry', Aircraft Engineering and Aerospace Technology, Vol. 69, No. 2, pp.151-159.

Phaal, R., Simonse, L. and den Ouden, E. (2008) 'Next generation roadmapping for innovation planning', International Journal of Technology Intelligence and Planning, Vol. 4, No. 2, pp.135-152.

Phaal, R. and Muller, G. (2009) 'An architectural framework for roadmapping: Towards visual strategy', Technological Forecasting and Social Change, Vol. 76, No. 1, pp.39-49. 
Royal Navy (2012) Type 23 frigates. Retrieved from http://www.royalnavy.mod.uk/The-Fleet/Ships/Frigates

Starbuck, W.H. and Milliken, F.J. (1988) 'Executives perceptual filters: What they notice and how they make sense', in Hambrick, D.C. (Ed.), The executive effect: Concepts and methods for studying top managers, JAI Press, Greenwich, CT, pp.35-65.

Stigliani, I. and Ravasi, D. (2012) 'Organizing thoughts and connecting brains: Material practices and the transition from individual to grouplevel prospective sensemaking', Academy of Management Journal, Vol. 55, No. 5, pp.1232-1259.

Taxén, L. and Lilliesköld, J. (2008) 'Images as action instruments in complex projects', International Journal of Project Management, Vol. 26, No. 5, pp.527-536.

Trabold, F.W. (1923) 'How a manager uses Gantt charts', in Clark, W. (Ed.), The Gantt chart: A working tool of management, The Ronald Press Company, New York, pp.143-150.

Weick, K.E. (1995) Sensemaking in organizations, Sage Publications, Thousand Oaks, CA.

Weick, K.E., Sutcliffe, K.M. and Obstfeld, D. (2005) 'Organizing and the process of sensemaking', Organization Science, Vol. 16, No. 4, pp.409421.

Yakura, E.K. (2002) 'Charting time: Timelines as temporal boundary objects', Academy of Management Journal, Vol. 45, No. 5, pp.956-970. 
Figure 1 One of the first charts produced by Henry Gantt (1919)

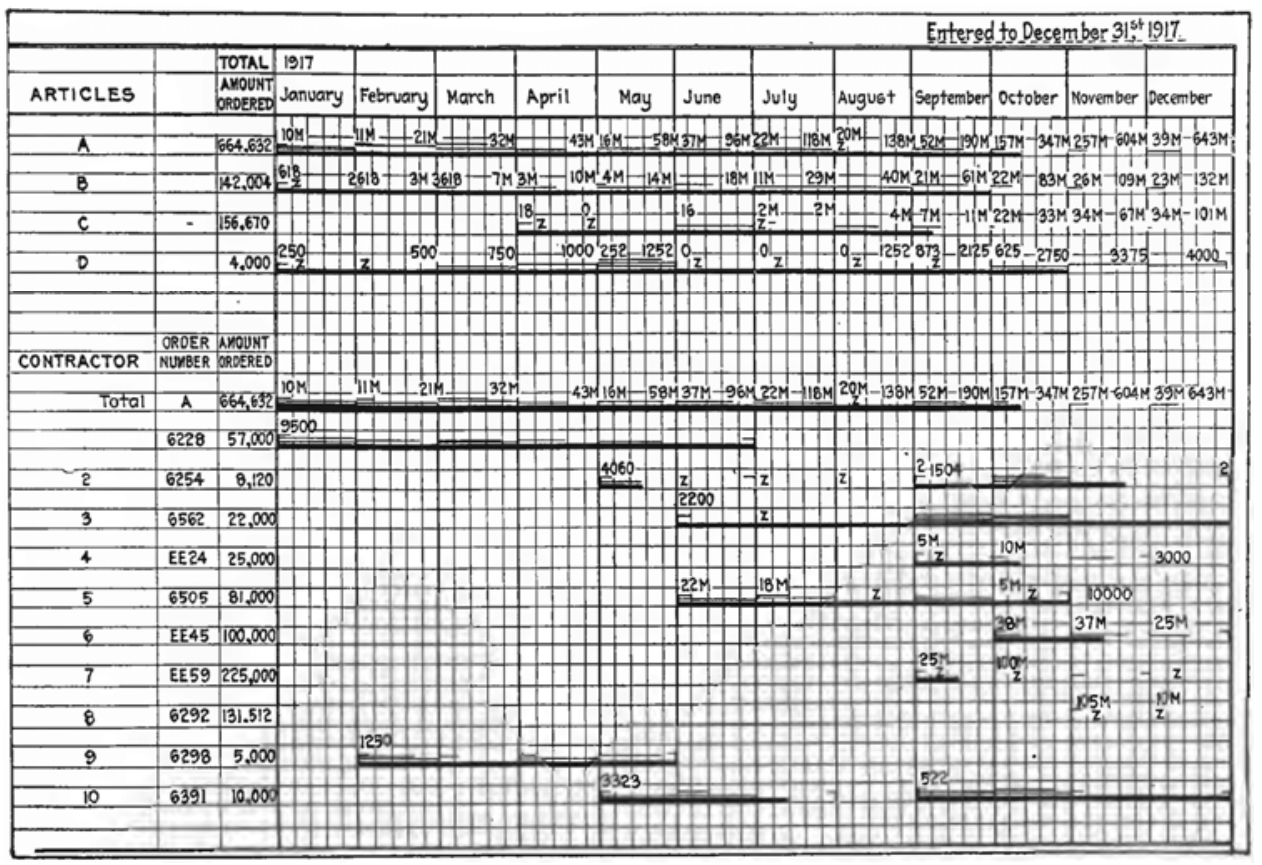


Figure 2 An early example of a Gantt chart for a naval application (Clark, 1923)

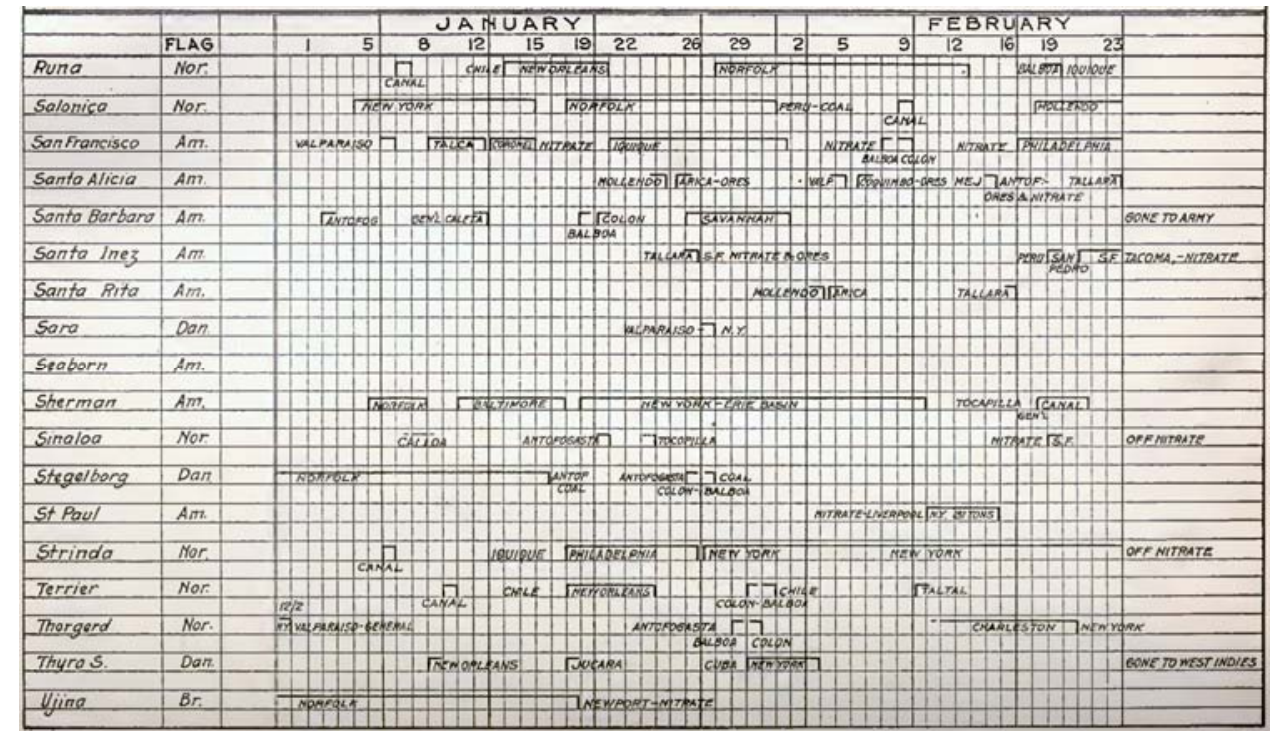


Figure 3 Visualisation of the Type 23 Fleet Upkeep Plan

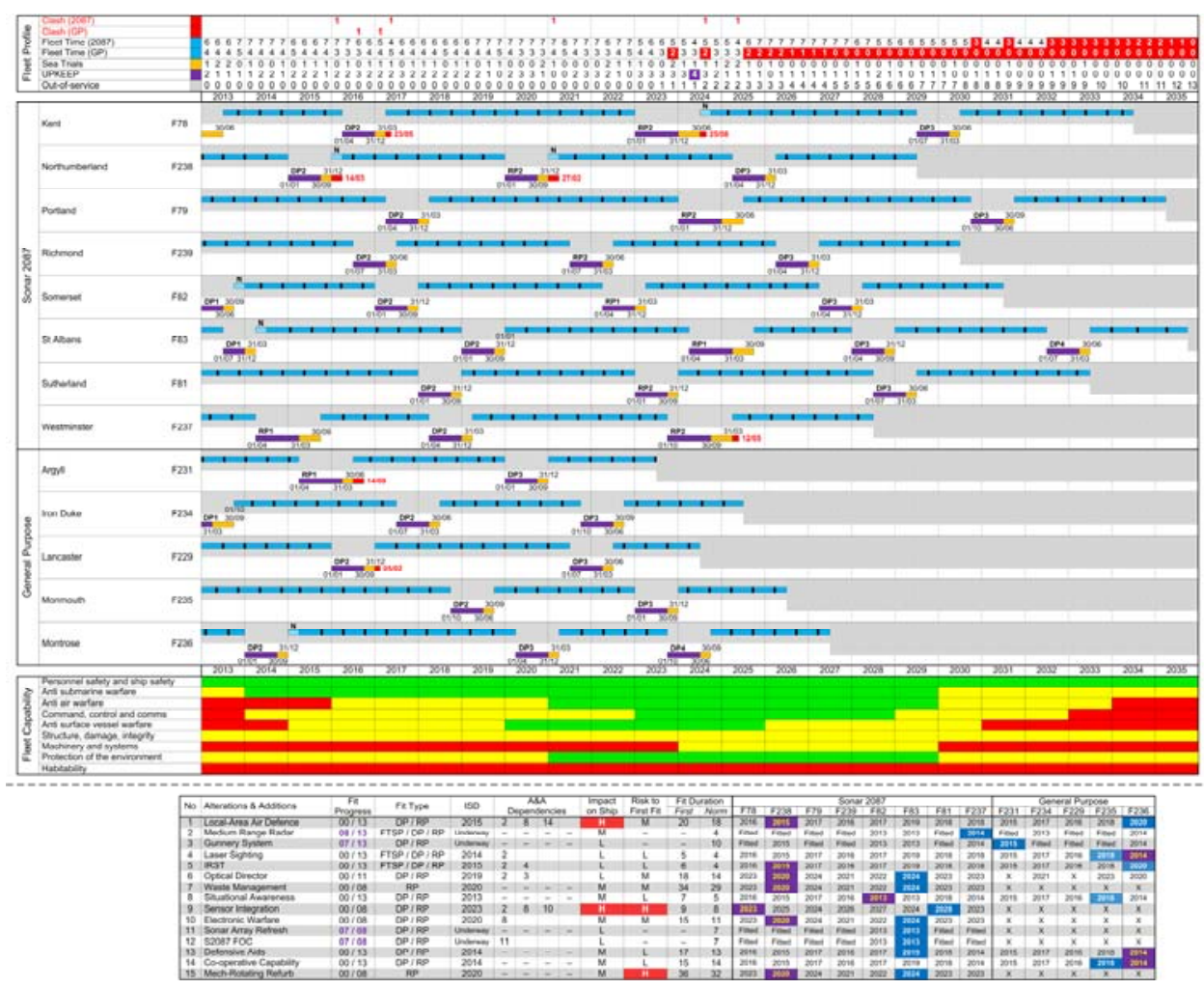


Figure 4 Principal visual forms

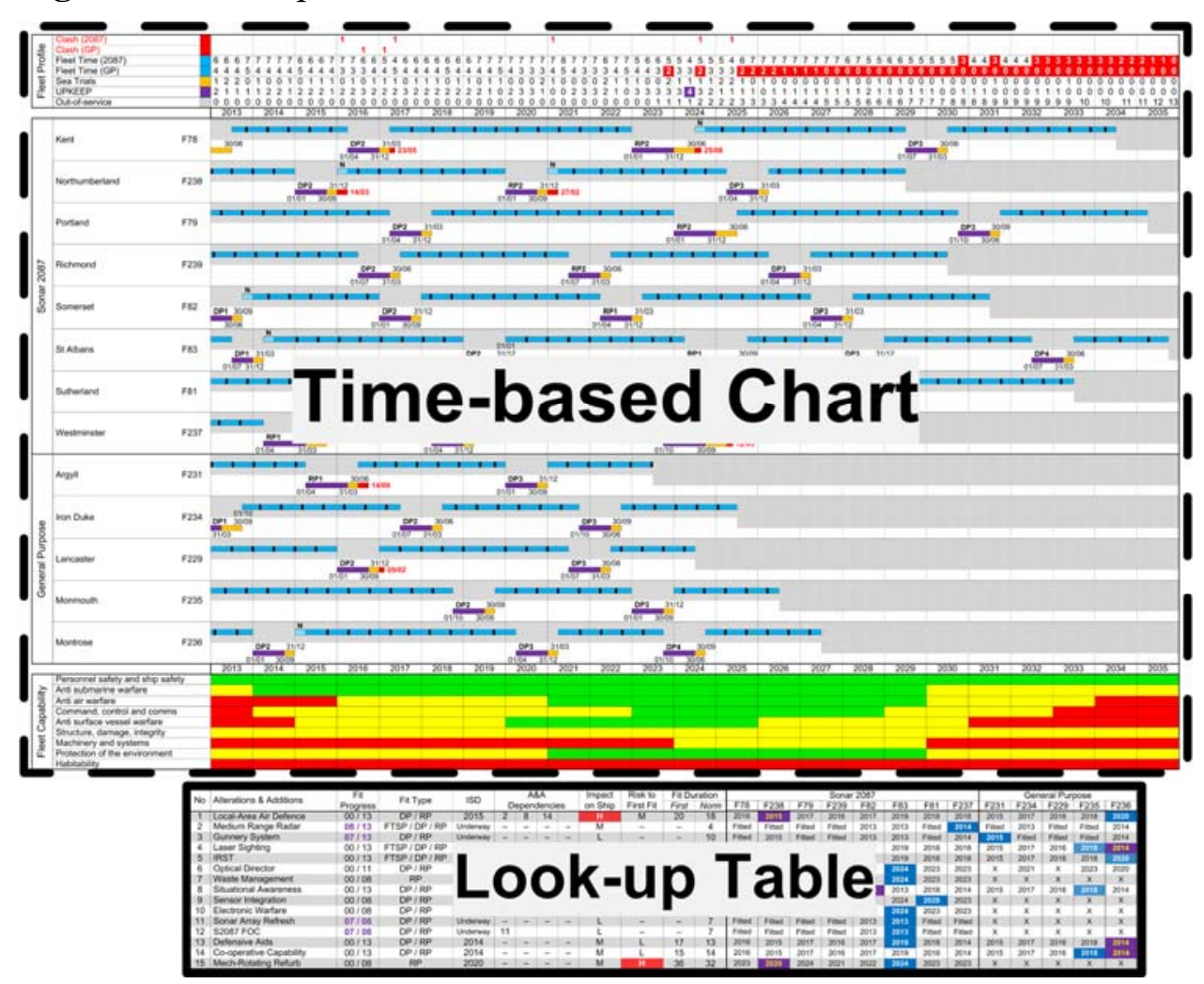


Figure 5 Visual canvas

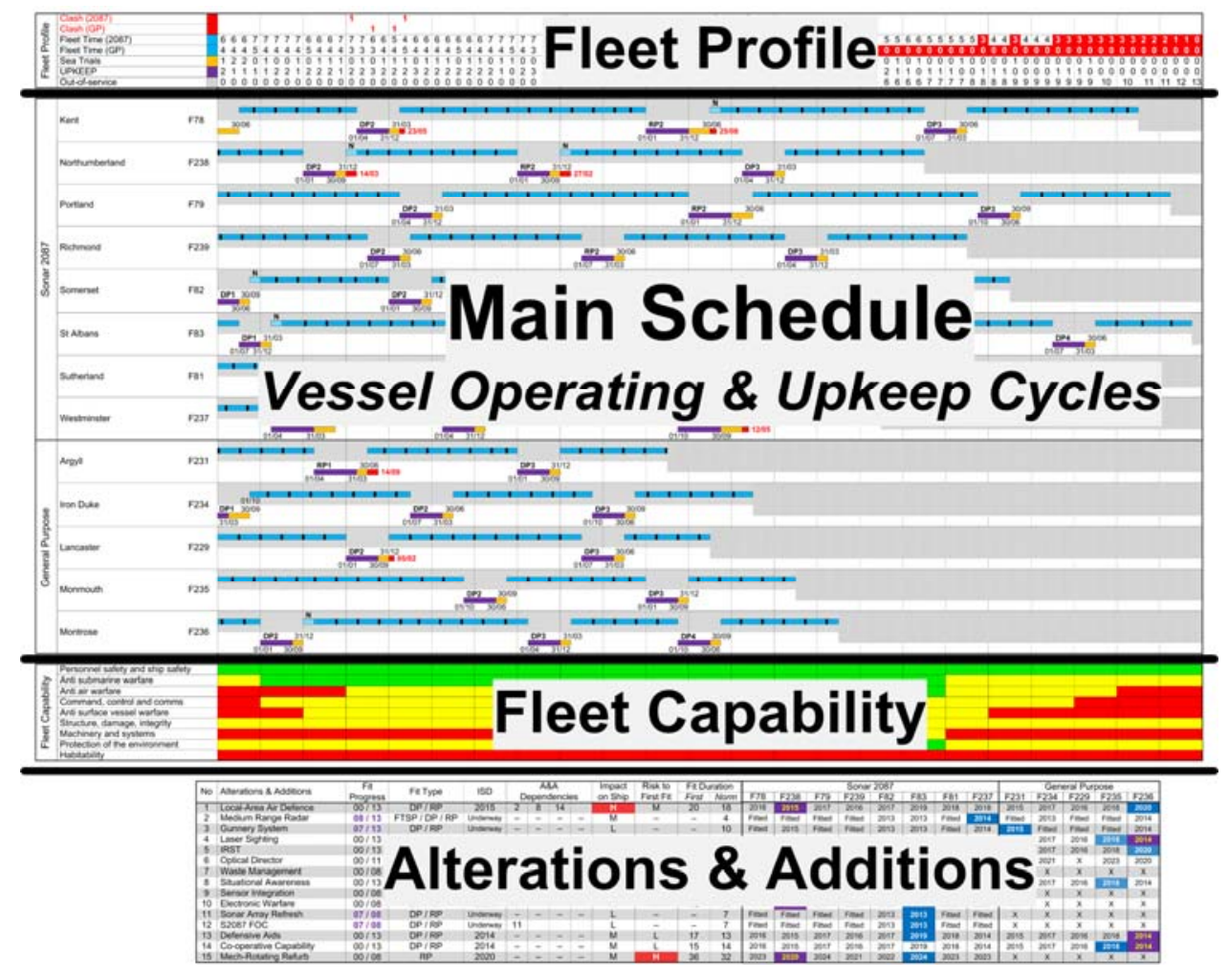


Figure 6 Main schedule

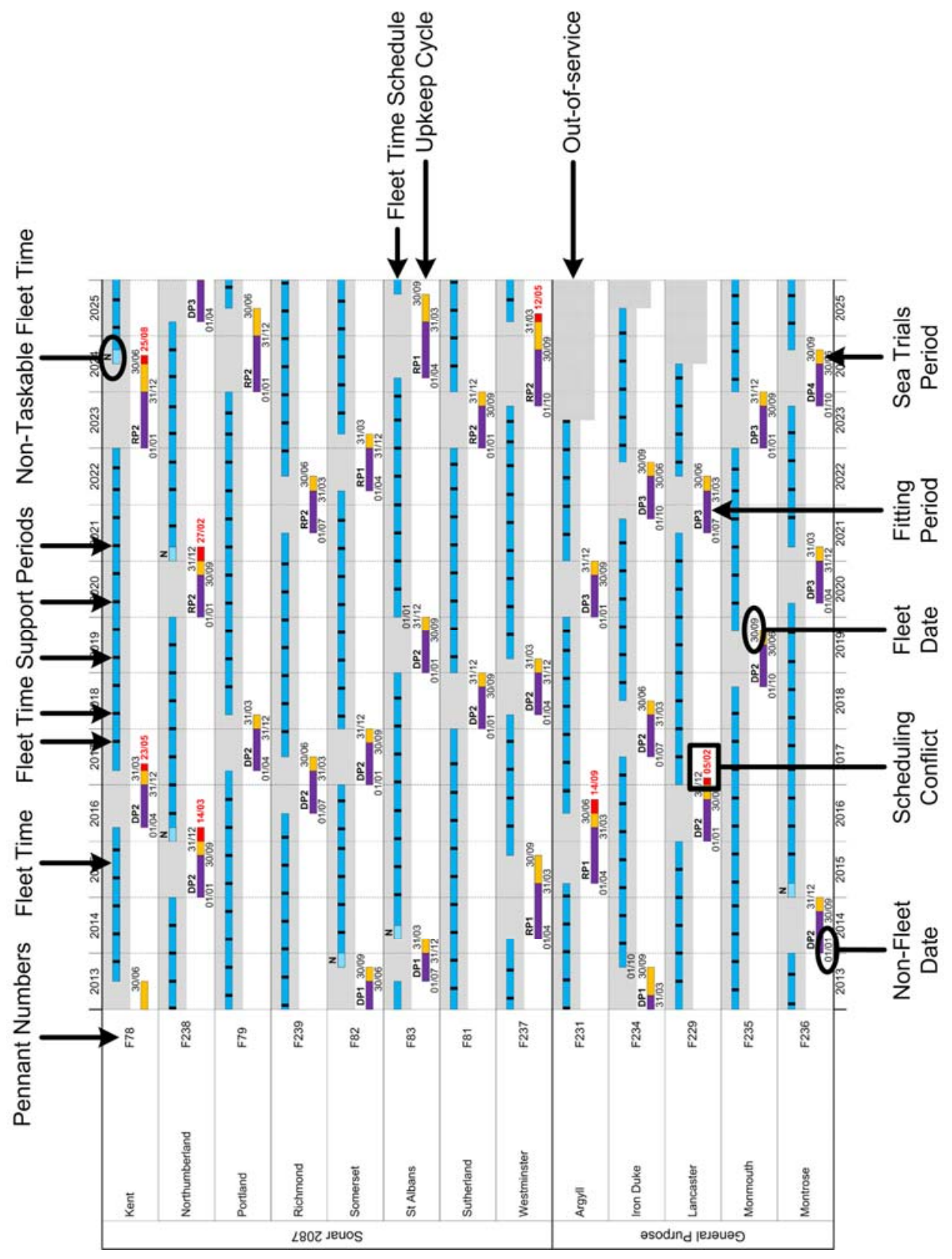


Figure $7 \quad$ Fleet profile

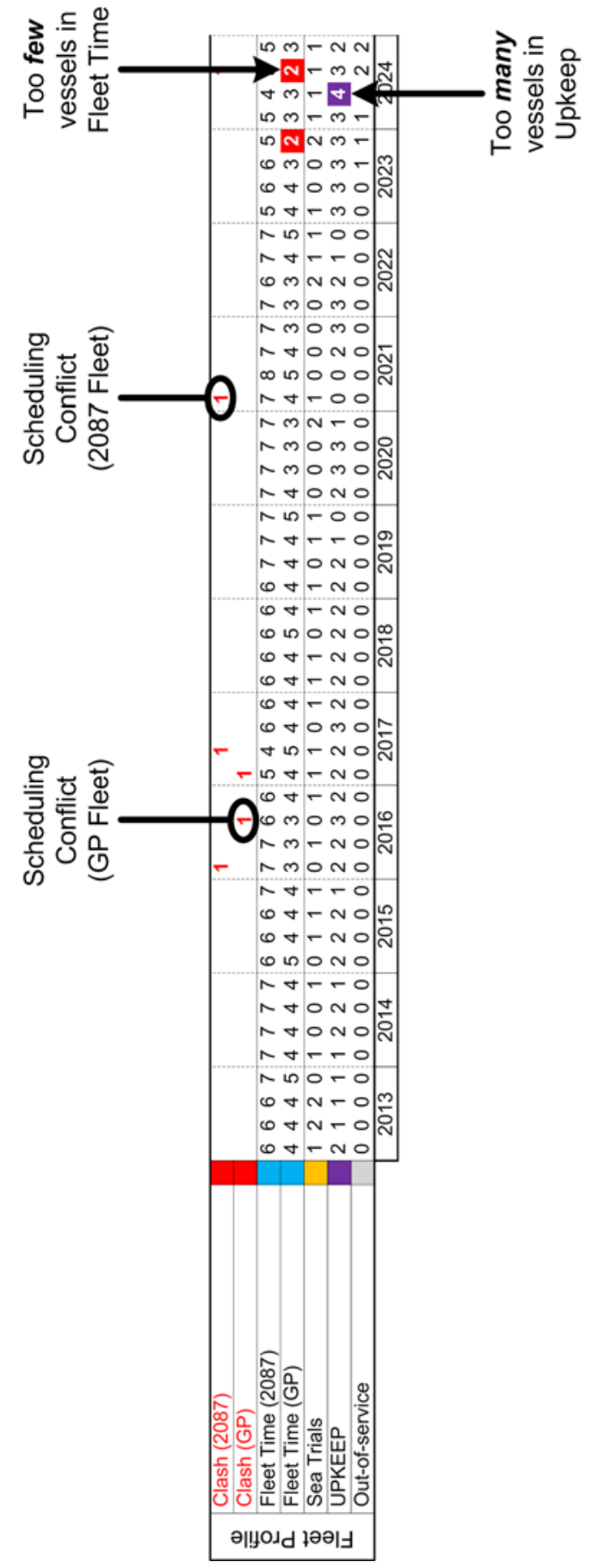


Figure 8 Fleet capability assessment

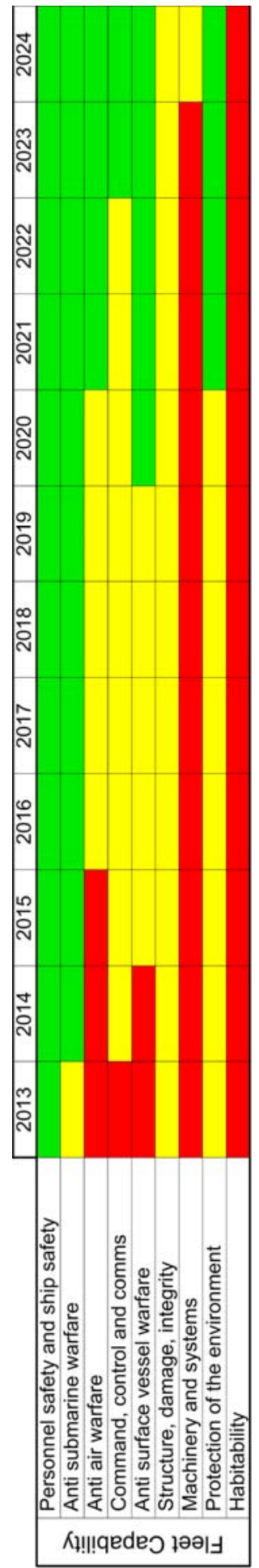


Figure 9a Alterations and Additions (supporting data)

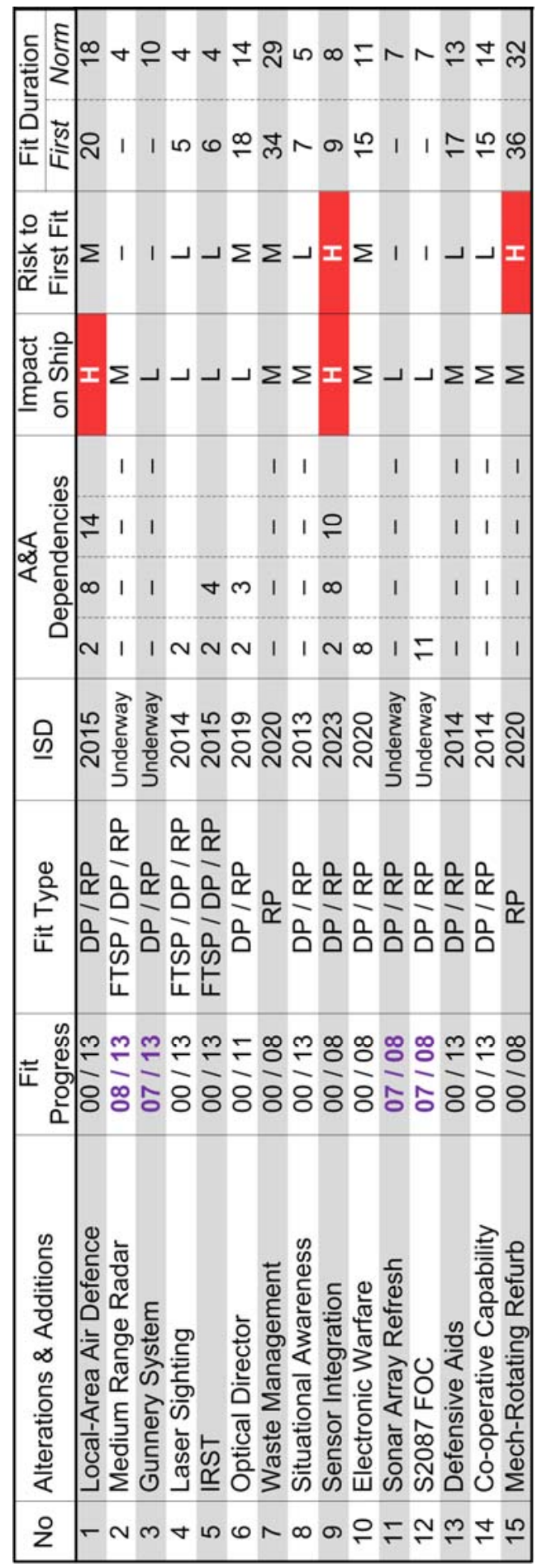


Figure 9b Alterations and Additions (vessel data)

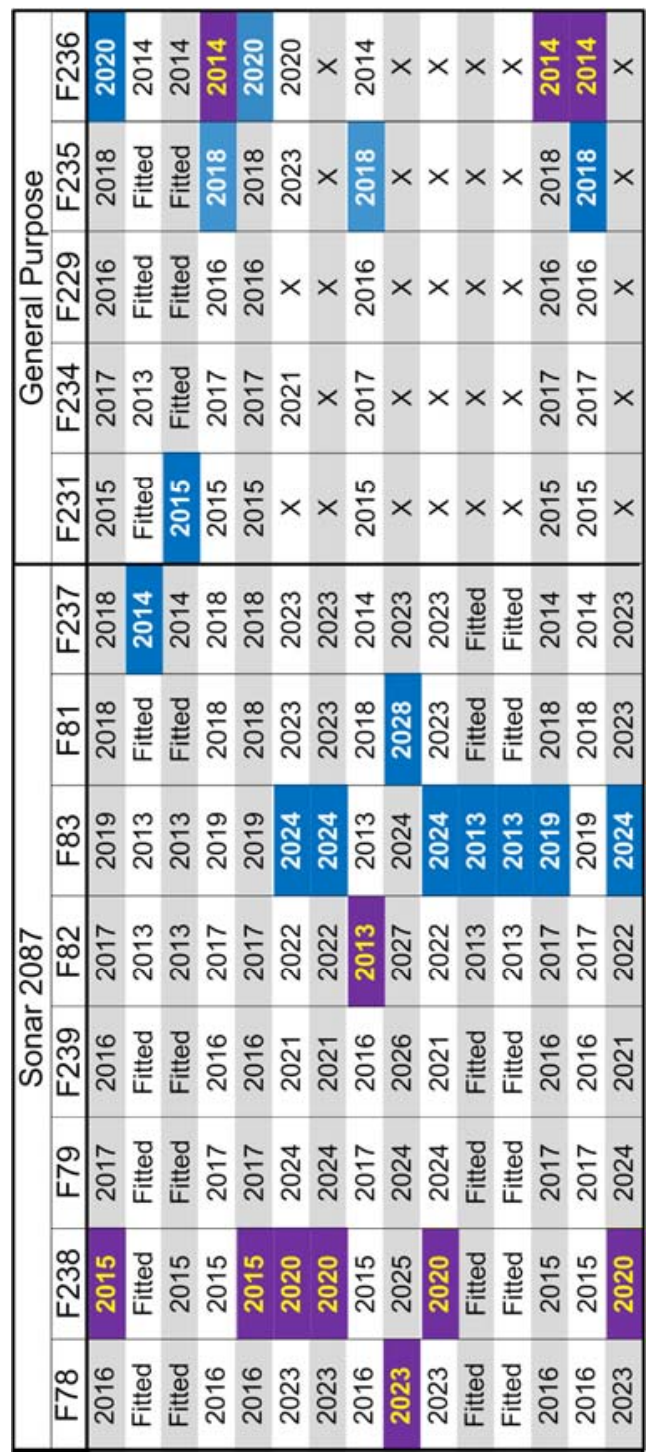

